\title{
DUKUNGAN ORANGTUA, EFIKASI DIRI PENGAMBILAN KEPUTUSAN KARIER, DAN PLANNED HAPPENSTANCE PADA SISWA SEKOLAH MENENGAH PERTAMA
}

\author{
Dara Suci Amini ${ }^{1}$ \& Rose Mini Agoes Salim
}

Fakultas Psikologi, Universitas Indonesia, Depok 16424, Indonesia

Korespondensi:

'e-mail:dara.suci@ui.ac.id

\begin{abstract}
Adolescence is an important period for career development. Parent support and adolescent's skills in seeking career opportunities from unexpected encounters contribute to adolescent's self-efficacy in career decision making. The present study examined the mediating role of planned happenstance in the relationship between career-related parent support and self-efficacy in career decision making among junior high school students. Participants comprised of 136 junior high school students. The instrument used in this study were the Indonesian translations of Career-Related Parent Support Scale, Career Decision Self-EfficacyShort Form, and Planned Happenstance Career Inventory. Results suggested that career-related parent support affects career decision-making self-efficacy directly or through the mediation of planned happenstance. The study concludes by outlining the importance of future studies to analyze the relationship between career-related parent support and planned happenstance.
\end{abstract}

\section{Article history:}

Received 12 August 2019

Received in revised form 6 October 2019

Accepted 7 November 2019

Available online 25 January 2020

\section{Keywords:}

career decision-making self-efficacy; middle school student;

parent support;

planned happenstance

\begin{abstract}
Abstrak - Masa remaja merupakan masa yang sangat penting dalam pengembangan karier. Dukungan orang tua dan juga keterampilan remaja dalam memanfaatkan peristiwa tak terduga sebagai peluang karier memengaruhi efikasi diri dalam membuat keputusan karier. Penelitian ini bertujuan untuk mengetahui peran planned happenstance dalam memediasi hubungan career-related parent support dan efikasi diri pengambilan keputusan karier pada siswa SMP. Subjek penelitian ini terdiri dari 136 siswa SMP. Alat ukur yang digunakan adalah Career-Related Parent Support Scale, Career Decision SelfEfficacy-Short Form, dan Planned Happenstance Career Inventory yang diadaptasi ke dalam Bahasa Indonesia. Hasil menunjukkan bahwa career-related parent support memengaruhi efikasi diri pengambilan keputusan karier secara langsung maupun melalui mediasi planned happenstance. Penelitian selanjutnya dapat menganalisis hubungan career-related parent support dan planned happenstance.
\end{abstract}

Kata Kunci: dukungan orangtua; efikasi diri pengambilan keputusan karier; planned happenstance; siswa SMP 


\section{PENDAHULUAN}

Jajak pendapat yang dilakukan pada 100 mahasiswa Universitas Udayana secara acak dari berbagai fakultas menemukan bahwa sebanyak 56\% mahasiswa yang menjadi partisipan merasa salah memilih jurusan kuliah (Widyaswara, 2016). Kemudian, penelitian Youthmanual pada siswa dan mahasiswa di seluruh Indonesia menemukan bahwa sebanyak 92\% siswa SMA/SMK sederajat mengalami kebingungan dan tidak tahu akan menjadi apa di masa depan dan 45\% mahasiswa merasa salah mengambil jurusan (Putri, 2018). Penelitian tersebut juga menemukan bahwa faktor ketidakyakinan terhadap kemampuan dan keterampilan yang dimiliki menjadi alasan para siswa merasa salah memilih jurusan.

Pada dasarnya, fenomena salah jurusan ini dapat dicegah dengan melihat proses perkembangan karier yang terjadi sejak usia dini. Di sepanjang proses perkembangan karier ini, masa yang paling penting adalah masa remaja yang dimulai pada Sekolah Menengah Pertama (SMP) (Papalia, 2014; Santrock, 2014). Hal ini dikarenakan pada masa remaja, seseorang mulai diberikan kepercayaan untuk membuat keputusan karier sendiri (Papalia, 2014; Santrock, 2014). Untuk dapat membuat keputusan karier secara mandiri, remaja membutuhkan keyakinan bahwa mereka memiliki kemampuan, keterampilan, dan kapasitas untuk menganalisis informasi yang ada sebagai pertimbangan untuk membuat keputusan karier tersebut (Sawitri, Creed, \& ZimmerGembeck, 2014).

Keyakinan tersebut disebut juga dengan career decision-making self-efficacy (CDSE). CDSE didefinisikan sebagai keyakinan seseorang terhadap kemampuan, keterampilan, dan kapasitas dirinya dalam membuat keputusan karier (Eva, Newman, Jiang, \& Brouwer, 2019; Taylor \& Popma, 1990). CDSE dibentuk dari self-appraisal (penilaian terhadap diri sendiri), occupational information (mengumpulkan informasi terkait pekerjaan impian), goal selection (membuat target), planning (membuat rencana strategi untuk mencapai target dengan memanfaatkan informasiinformasi yang ada), dan problem solving (penyelesaian terhadap masalah apapun yang menghalangi perjalanan menuju karier yang diinginkan) (Choi dkk., 2012). Choi dkk. juga menekankan bahwa CDSE merupakan prediktor paling kuat dalam perkembangan karier seseorang. Hal ini sejalan dengan beberapa penelitian yang menyebutkan bahwa CDSE dianggap sebagai sebuah konstruksi yang berguna untuk perkembangan karier yang matang (Betz \& Luzzo, 1996; Kim, Rhee, Ha, Yang, \& Lee, 2016). 
Dalam membangun keyakinan terhadap kemampuan dan kapasitas yang dimiliki untuk membuat keputusan karier, remaja membutuhkan dukungan dari orang tua (Tien, Lin, \& Chen, 2005). Dukungan orang tua terkait perkembangan karier ini disebut career-related parent support (CRPS). Turner, Alliman-Brissett, Lapan, Udipi, dan Ergun (2019) mendefinisikan CRPS sebagai dukungan yang diberikan orang tua dalam hal pendidikan dan pekerjaan anak. Dukungan-dukungan orang tua ini termasuk modeling, bantuan finansial, menyediakan fasilitas, dorongan verbal, dukungan emosional (cinta dan perhatian), dan ketersediaan informasi karier (Mao, Hsu, \& Fang, 2017; Sawitri \& Creed, 2015; Suh \& Flores, 2017; Turner, Alliman-Brissett, Lapan, Udipi, \& Ergun, 2019). Penelitian mengenai hubungan antara CRPS dan CDSE memang masih sedikit, namun terdapat beberapa penelitian yang menjadi petunjuk adanya hubungan antara keduanya, yaitu dukungan orang tua secara signifikan memengaruhi CDSE (Shin \& Lee, 2018; Tolentino, Garcia, Toledano, Rafferty, \& Restubog, 2011).

CRPS merupakan faktor eksternal, sedangkan efikasi diri dibentuk oleh faktor eksternal dan faktor internal (Brown, 2002). Salah satu faktor internal yang ditemukan memengaruhi CDSE secara signifikan adalah keterampilan memanfaatkan kejadian tak terduga sebagai peluang (Krumboltz, 2009). Hal ini disebut sebagai planned happenstance, yang didefinisikan sebagai keterampilan dan kemampuan individu untuk menangkap kejadian tak terduga sebagai peluang (Kim, Kim, Yang, Yaung, \& Lee, 2017). Krumboltz (2009) menyatakan bahwa orang tua memiliki peranan yang krusial dalam membentuk keterampilan planned happenstance ini. Misalnya, orang tua memberikan kesempatan yang luas bagi remaja untuk memperoleh pengalaman dan mengembangkan kemampuannya (Kim dkk., 2016; Kim dkk., 2017; Lim \& You, 2019). Berbekal hal ini, remaja kemudian membentuk keterampilan untuk memanfaatkan peluang tak terduga yang menghampirinya sebagai sebuah peluang karier (Kim dkk., 2017).

Berdasarkan uraian tersebut, maka hipotesis dalam penelitian ini adalah planned happenstance memediasi hubungan antara CRPS dan CDSE. Selanjutnya, hasil penelitian ini dapat digunakan sebagai pedoman dalam membuat strategi pengembangan karier yang melibatkan orang tua siswa. Dengan demikian, intervensi yang diberikan tepat sasaran dan tepat guna. Selanjutnya, fenomena salah jurusan ini dapat diminimalkan. 


\section{METODE}

\section{Partisipan}

Partisipan dalam penelitian ini adalah para siswa Sekolah Menengah Pertama (SMP) sebanyak 51 orang siswa laki-laki dan 85 orang siswa perempuan $(\mathrm{n}=136$ siswa) dengan usia ratarata 14 tahun. Pemilihan partisipan dilakukan dengan teknik convenience sampling. Proses perekrutan partisipan dilakukan dengan menyebar kuesioner online di sosial media. Kuesioner ini dilengkapi dengan informed consent yang menyatakan bahwa siswa yang menjadi partisipan penelitian ini telah mendapatkan persetujuan orang tua untuk mengisi kuesioner tersebut. Kuesioner disebarkan pada grup-grup orang tua dan wali kelas yang kemudian diisi oleh siswa sesuai kriteria yang ditentukan.

\section{Desain}

Penelitian ini merupakan penelitian kuantitatif non-eksperimental, cross-sectional dengan variabel dependen adalah CDSE, variabel independen adalah CRPS, dan variabel mediator adalah planned happenstance yang diukur menggunakan instrumen Career Decision Making Self-Efficacy Scale-Short Form (CDSE-SF), Career-Related Parent Support Scale (CRPSS), dan Planned Happenstance Career Inventory (PHCI).

CDSE diukur dengan menggunakan 25 butir Career Decision Making Self-Efficacy ScaleShort Form (CDSE-SF) (Betz, Klein, \& Taylor, 1996). Skala yang digunakan merupakan skala yang telah diadaptasi terlebih dahulu ke dalam bahasa Indonesia oleh Sawitri (2009). Skala ini terdiri dari 6 poin skala Likert dengan rentang 1-6 ('Sama Sekali Tidak Yakin' sampai dengan 'Sangat Yakin'). Koefisien reliabilitas (Cronbach's Alpha) yang dimiliki skala ini sebesar 917 dengan corrected item-total correlation mulai dari .245 hingga .693, kecuali untuk butir nomor 13 yang tidak digunakan karena hanya memiliki validitas sebesar .122. Hasil ini menunjukkan bahwa alat ukur CDSE-SF dengan total 24 butir valid dan reliabel untuk mengukur CDSE pada siswa SMP.

Peneliti terlebih dahulu meminta izin penggunaan instrumen pada penerjemah dan pengembang pertama CDSE-SF versi Bahasa, yaitu Dian Ratna Sawitri melalui email. Kemudian, dilanjutkan dengan meminta expert judgment oleh dosen Fakultas Psikologi Universitas Indonesia yang memiliki keahlian dalam bidang pengembangan karier untuk menganalisis instrumen terlebih 
dahulu. Terakhir, peneliti menyebarkan kuesioner online pada beberapa siswa SMP di Jabodetabek untuk memeriksa keterbacaan butir-butir tersebut sebelum pengambilan data dilakukan.

Alat ukur CRPSS yang digunakan dalam penelitian ini terdiri dari 27 butir. Skala ini menggunakan empat dimensi, yaitu instrumental assistance, career-related modeling, dan emotional support yang masing-masing memiliki 7 butir, serta verbal encouragement yang memiliki 6 butir. CRPSS menggunakan 6 poin skala Likert dengan rentang 1-6 ('Sangat Tidak Setuju' sampai dengan 'Sangat Setuju'). Koefisien reliabilitas (Cronbach's Alpha) skala ini adalah .918 dengan corrected item-total correlation mulai dari .277 hingga .753. Hal ini menunjukkan bahwa alat ukur CRPSS cukup valid dan reliabel untuk mengukur CRPSS pada siswa SMP.

Setelah mendapatkan izin dari Sherri Turner sebagai correspondent author dalam penelitian pengembangan alat ukur CRPSS, peneliti menerjemahkan butir dalam instrumen ini dari Bahasa Inggris ke Bahasa Indonesia dengan prosedur forward and backward translation. Selanjutnya, instrumen melalui proses expert judgement dan uji keterbacaan sebelum pengambilan data dilakukan.

Planned Happenstance Career Inventory (PHCI) adalah skala yang dikembangkan oleh Kim dkk. (2014) berdasarkan Planned Happenstance Theory yang dikembangkan oleh Mitchell pada tahun 1999 (Lee dkk., 2017). PHCI memiliki lima subskala, yaitu rasa ingin tahu, ketekunan, fleksibilitas, optimisme, dan pengambilan risiko. Terdapat 5 butir untuk setiap subskala yang dinilai pada skala Likert dengan rentang 1-5 ('Saya Tidak Setuju Sama Sekali' sampai dengan 'Saya Sangat Setuju'). Dalam penelitian ini, koefisien reliabilitas (Cronbach's Alpha) alat ukur PHCI adalah .918 dengan corrected item-total correlation mulai dari .378 hingga .697, kecuali butir nomor 6 yang memiliki validitas .146. Hal ini menunjukkan bahwa alat ukur PHCI valid dan reliabel untuk mengukur PHS pada siswa SMP.

Seperti CRPSS, peneliti juga melakukan proses permintaan izin pada Sang Min Lee sebagai correspondent author dalam penelitian pengembangan alat ukur PHCI ini. Selanjutnya, peneliti melakukan proses translation, expert judgement, dan uji keterbacaan sebelum pengambilan data.

\section{Teknik Analisis}

Untuk menguji hipotesis penelitian, peneliti terlebih dahulu melakukan analisis korelasi untuk mengetahui hubungan antar variabel penelitian menggunakan teknik Pearson Correlation, kemudian dilanjutkan dengan uji regresi dan uji mediasi dengan menggunakan macro PROCESS 
V3.3 dari Hayes (Hayes, 2017). Teknik analisis tersebut digunakan untuk menguji hubungan CRPS dalam CDSE pada siswa SMP melalui mediasi planned happenstance.

\section{ANALISIS DAN HASIL}

Menurut hasil analisis korelasi seperti yang tampak dalam Tabel 1, CRPS dan planned happenstance berkorelasi positif dan signifikan $(r=.360 ; p=.000)$. Hal ini menunjukkan bahwa semakin tinggi dukungan orang tua yang diterima siswa, semakin tinggi pula kemampuan siswa dalam memanfaatkan peluang karier yang ada. Kemudian, planned happenstance juga berkorelasi positif dan signifikan dengan CDSE $(r=.690 ; p=.000)$. Hasil ini menunjukkan bahwa semakin tinggi kemampuan siswa dalam memanfaatkan peluang karier yang ada, semakin tinggi pula efikasi diri siswa SMP dalam membuat keputusan karier.

Tabel 1.

Matriks Korelasi Antar Variabel Penelitian

\begin{tabular}{llll}
\hline Alat ukur $(M, S D$, Cronbach's $\alpha)$ & (1) & $\mathbf{( 2 )}$ & (3) \\
\hline (1) CDSE $(4.76 ; 6.73 ; .917)$ & - & $.690^{* *}$ & $.416^{* *}$ \\
(2) PHS $(5.02 ; .584 ; .918)$ & & - & $.360^{* *}$ \\
(3) CRPSS $(5.00 ; .698 ; .918)$ & & \multicolumn{2}{c}{-} \\
\hline Keterangan: CDSE = career decision & -making & self--efficacy; \\
PHS = planned happenstance; CRPS = career-related parent support; \\
**signifikansi pada level $p<.01 ;$ *signifikansi pada level $p<.05$
\end{tabular}

Selanjutnya, hasil uji regresi seperti yang tampak dalam Gambar 1 menunjukkan planned happenstance memengaruhi CDSE secara signifikan $(b=.715 ; p=.000)$. CRPS juga menunjukkan kontribusi signifikan terhadap planned happenstance $(a=.301 ; p=.000)$ dan $\operatorname{CDSE}\left(c^{\prime}=.185\right.$; $p=.003)$. Berdasarkan hasil uji diketahui pula bahwa efek tidak langsung CRPS terhadap CDSE terjadi secara signifikan $(a b=.215 ; p=.003)$. Hasil ini menunjukkan bahwa CRPS memengaruhi CDSE baik secara langsung maupun secara tidak langsung melalui media planned happenstance. Oleh karena itu, dapat disimpulkan bahwa hipotesis dalam penelitian ini diterima. 


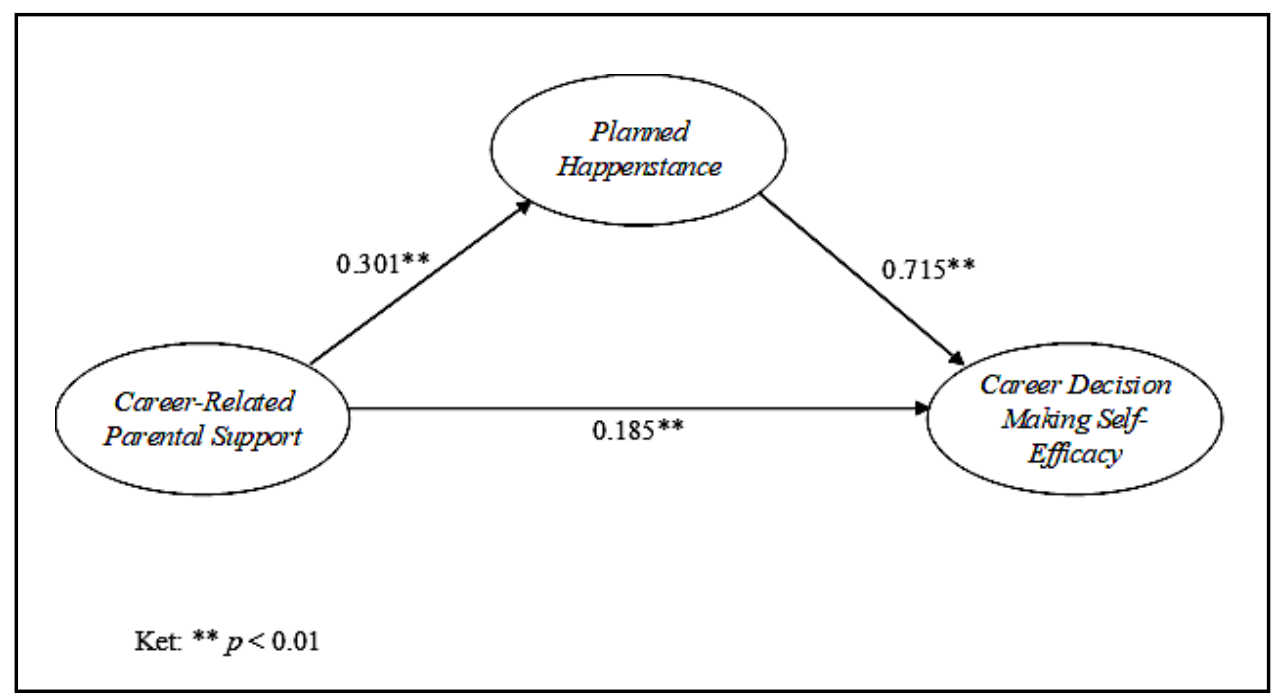

Gambar 1. Model PHS memediasi CRPS dan CDSE

Selanjutnya, berdasarkan uji beda (lihat Tabel 2), diketahui bahwa tidak terdapat perbedaan planned happenstance, CRPS, dan CDSE yang signifikan antara remaja laki-laki dan remaja perempuan. Hal ini dikarenakan perlakuan yang sama dari orang tua, baik pada remaja laki-laki maupun remaja perempuan dalam hal dukungan sosial, sehingga planned happenstance yang terbentuk sama-sama meningkatkan CDSE pada kedua kelompok remaja tersebut.

Tabel 2.

Hasil Uji Beda Berbagai Variabel Penelitian pada Lelaki dan Perempuan

\begin{tabular}{cccccccc}
\hline \multicolumn{3}{c}{ Equality of Variance } & \multicolumn{5}{c}{ t-test for Equality of Means } \\
\cline { 2 - 8 } & \multirow{2}{*}{ Sig. } & $t$ & $d f$ & Sig. (2-tailed) & $\begin{array}{c}\text { Mean } \\
\text { Difference }\end{array}$ & $\begin{array}{c}\text { Std. Error } \\
\text { Difference }\end{array}$ \\
\hline \multirow{2}{*}{ CDSE } & .024 & .877 & -.060 & 134 & .952 & -.008 & .131 \\
& & & -.061 & 113.484 & .951 & -.008 & .128 \\
PHS & 3.230 & .075 & -1.103 & 134 & .272 & -.125 & .114 \\
& & & -1.072 & 95.993 & .287 & -.125 & .117 \\
CRPS & 3.251 & .074 & .319 & 134 & .750 & .039 & .123 \\
& & & .337 & 122.889 & .737 & .039 & .116 \\
\hline
\end{tabular}

\section{DISKUSI}

Studi ini menunjukkan bahwa planned happenstance memediasi hubungan CRPS dan CDSE. Namun, hasil penelitian juga menunjukkan bahwa mediasi ini hanya partial. Artinya, CRPS memengaruhi CDSE dengan meningkatkan keterampilan planned happenstance terlebih dahulu, 
kemudian meningkatkan CDSE (pengaruh tidak langsung) atau CRPS memengaruhi CDSE secara langsung (pengaruh langsung). Walaupun demikian, hubungan tidak langsung CRPS dan CDSE melalui PHS lebih besar daripada hubungan secara langsung dari CRPS ke CDSE. Hal ini menunjukkan bahwa walaupun dukungan orang tua cukup mampu meningkatkan efikasi diri dalam membuat keputusan karier, namun akan lebih baik jika orang tua membantu remaja atau siswa SMP meningkatkan keterampilan planned happenstance terlebih dahulu untuk meningkat CDSE.

Hal ini sejalan dengan penelitian (Zaroh, 2018) yang menyatakan bahwa remaja akan memiliki efikasi diri yang rendah dalam membuat keputusan karier karena kurangnya keterampilan dan kemampuan mereka dalam memanfaatkan peluang karier tak terduga yang menghampiri mereka. Sawitri dkk. (2014) mengungkapkan bahwa peluang karier dari kejadian-kejadian tak terduga ini dapat dikembangkan jika siswa mendapatkan dukungan dari orang tuanya. Hasil ini juga sejalan dengan penelitian yang dilakukan terhadap siswa di Negara Asia, seperti Cina dan India bahwa dukungan orang tua sangat memengaruhi efikasi diri mereka dalam membuat keputusan karier (Guan dkk., 2015; S. Kim, Ahn, \& Fouad, 2015; Olle \& Fouad, 2015). Guan dkk. (2015) juga menyatakan secara spesifik bahwa dukungan orang tua ini sangat dibutuhkan terutama pada remaja yang lebih muda. Sedangkan, pada remaja akhir atau dewasa awal, dukungan yang dibutuhkan lebih banyak dari kelompok teman sebaya atau pasangan.

Berbeda dengan remaja di Amerika dan Eropa yang cenderung lebih mandiri dan individual, pengambilan keputusan karier remaja di Indonesia sangat dipengaruhi oleh orang tua (Sawitri \& Creed, 2017). Sawitri dkk. (2014) menyatakan bahwa peran orang tua terhadap efikasi diri remaja dalam membuat keputusan karier dapat dilihat dari upaya orang tua mendorong remaja untuk mengikuti karier orang tua atau menjalani karier yang disarankan orang tua.

Penelitian ini menemukan bahwa jenis kelamin tidak membuat perbedaan yang signifikan dalam hubungan antara planned happenstance, CRPS, dan CDSE. Hasil ini sejalan dengan penelitian Betz dan Luzzo (1996) yang menyatakan bahwa jenis kelamin tidak memberikan pengaruh yang signifikan terhadap pembentukan CDSE.

\section{SIMPULAN DAN SARAN}

\section{Simpulan}

Penelitian ini menemukan bahwa career-related parent support (CRPS) secara signifikan memengaruhi career decision making self-efficacy (CDSE) (efikasi diri pengambilan keputusan 
karier). Hubungan ini dapat terjadi secara langsung maupun tidak langsung melalui mediasi planned happenstance. Kemudian, tidak terdapat perbedaan yang signifikan antara remaja laki-laki dan remaja perempuan dalam hubungan ketiga variabel tersebut.

\section{Saran Teoretis}

Keterbatasan penelitian ini adalah jumlah sampel penelitian yang masih cukup kecil jika dibandingkan dengan populasi siswa SMP yang ada di Jabodetabek dan Jawa Barat. Hal ini membuat hasil penelitian akan sulit untuk digeneralisasikan ke dalam kelompok populasi yang lebih besar. Oleh karena itu, saran untuk penelitian selanjutnya adalah menambah jumlah sampel penelitian untuk memperoleh gambaran yang lebih besar, sehingga data dapat digeneralisasikan untuk remaja di Indonesia.

\section{Saran Praktis}

Oleh karena penelitian yang menganalisis hubungan career-related parent support dan planned happenstance masih sangat terbatas, Maka hal ini dapat menjadi peluang untuk penelitian terkait perkembangan karier di Indonesia mengingat peran orang tua di Indonesia yang sangat memengaruhi perkembangan karier remaja. Selain itu, (Rueger, Malecki, \& Demaray, 2009) menyebutkan bahwa sumber dukungan sosial tidak hanya datang dari orang tua, namun juga dari teman, guru, pasangan, atau significant others. Maka, penelitian terkait pengaruh dukungan sosial terhadap efikasi diri pengambilan keputusan karier ke depannya dapat dikembangkan dengan menganalisis pengaruh dari sumber-sumber dukungan sosial yang lain.

\section{REFERENSI}

Betz, N. E., Klein, K. L., \& Taylor, K. M. (1996). Evaluation of a short form of the career decisionmaking self-efficacy scale. Journal of Career Assessment, 4(1), 47-57. doi: $10.1177 / 106907279600400103$

Betz, N. E., \& Luzzo, D. A. (1996). Career assessment and the career decision-making self-efficacy scale. Journal of Career Assessment, 4(4), 413-428. doi: 10.1177/106907279600400405

Brown, D. (2002). Career choice and development (4th ed.). San Francisco, CA: Jossey-Bass.

Choi, B. Y., Park, H., Yang, E., Lee, S. K., Lee, Y., \& Lee, S. M. (2012). Understanding career decision self-efficacy: A meta-analytic approach. Journal of Career Development, 39(5), 
443-460. doi: 10.1177/0894845311398042

Eva, N., Newman, A., Jiang, Z., \& Brouwer, M. (2019). Career optimism : A systematic review and agenda for future research. Journal of Vocational Behavior. doi: 10.1016/j.jvb.2019.02.011

Guan, Y., Chen, S. X., Levin, N., Bond, M. H., Luo, N., Xu, J., .. Li, Y. (2015). Differences in career decision- making profiles between American and Chinese university students: The relative strength of mediating mechanisms across cultures. Journal of Cross-Cultural Psychology, 46(6), 856-872. doi: 10.1177/0022022115585874

Hayes, A. F. (2017). Introduction to mediation, moderation, and conditional process analysis: A regression-based approach (2nd ed.). New York, NY: Guilford Press.

Kim, S. R., Ahn, T., \& Fouad, N. (2015). Family influence on Korean students' career decisions. Journal of Career Assessment, 24(3), 513-526. doi: 10.1177/1069072715599403

Kim, S. R., Kim, B., Yang, N. Y., Yaung, H., \& Lee, S. M. (2017). Longitudinal changes of planned happenstance skills by gender, community types, and employment status in a sample of college students in school-to-work transition. Journal of Employment Counseling, 54(4), 183-191. doi: 10.1002/joec.12066

Kim, B., Jung, S. H., Jang, S. H., Lee, B., Rhee, E., Cho, S. H., \& Lee, S. M. (2014). Construction and initial validation of the planned happenstance career inventory. Career Development Quarterly, 62(3), 239-253. doi: 10.1002/j.2161-0045.2014.00082.x

Kim, B., Rhee, E., Ha, G., Yang, J., \& Lee, S. M. (2016). Tolerance of uncertainty: Links to happenstance, career decision self-efficacy, and career satisfaction. Career Development Quarterly, 64(2), 140-152. doi: 10.1002/cdq.12047

Krumboltz, J. D. (2009). The happenstance learning theory. Journal of Career Assessment, 17(2), 135-154. doi: 10.1177/1069072708328861

Lee, J. H., Cho, S., Lee, S., Eum, W. J., Jang, H., Suh, S., \& Lee, S. M. (2017). Initial validation of the planned happenstance career inventory-English version. Career Development Quarterly, 65(4), 366-378. doi: 10.1002/cdq.12114

Lim, S. A., \& You, S. (2019). Long-term effect of parents' support on adolescents' career maturity. Journal of Career Development, 46(1), 48-61. doi: 10.1177/0894845317731866

Mao, C., Hsu, Y., \& Fang, T. (2017). Mediating effect of career decision self-efficacy on the relationship between parental support and indecision in Taiwan. Journal of Career Development, 44(6), 471-484. doi: 10.1177/0894845316663319

Olle, C. D., \& Fouad, N. A. (2015). Parental support, critical consciousness, and agency in career 
decision making for urban students. Journal of Career Assessment, 23(4), 533-544. doi: $10.1177 / 1069072714553074$

Papalia, D. (2014). Experience human development. New York, NY: McGraw-Hill Higher.

Putri, N. (2018). Angka siswa yang salah pilih jurusan masih tinggi. Youthmanual. Ditemu kembali dari http://www.skystarventures.com/youthmanual-angka-siswa-yang-salah-pilih-jurusanmasih-tinggi/

Rueger, S. Y., Malecki, C. K., \& Demaray, M. K. (2009). Relationship between multiple sources of perceived social support and psychological and academic adjustment in early adolescence: Comparisons across gender. Journal of Youth and Adolescence, 39(1), 47-61. doi: 10.1007/s10964-008-9368-6

Santrock, J. W. (2014). Essentials of life-span development (4th ed.). New York, NY: McGrawHill.

Sawitri, D. R. (2009). Pengaruh status identitas dan efikasi diri keputusan karir terhadap keraguan mengambil keputusan karir pada siswa SMA kelas 12. Jurnal Psikologi Undip, 5(2), 1-14.

Sawitri, D. R., \& Creed, P. A. (2015). Perceived career congruence between adolescents and their parents as a moderator between goal orientation and career aspirations. Personality and Individual Differences, 81, 29-34. doi: 10.1016/j.paid.2014.12.061

Sawitri, D. R., \& Creed, P. A. (2017). Collectivism and perceived congruence with parents as antecedents to career aspirations: A social cognitive perspective. Journal of Career Development, 44(6), 530-543. doi: 10.1177/0894845316668576

Sawitri, D. R., Creed, P. A., \& Zimmer-Gembeck, M. J. (2014). Parental influences and adolescent career behaviours in a collectivist cultural setting. International Journal for Educational and Vocational Guidance, 14(2), 161-180. doi: 10.1007/s10775-013-9247-x

Shin, Y. J., \& Lee, J. Y. (2018). Predictors of career decision self-efficacy: Sex, socioeconomic status (SES), classism, modern sexism, and locus of control. Journal of Career Assessment, 26(2), 322-337. doi: 10.1177/1069072717692981

Suh, H. N., \& Flores, L. Y. (2017). Relative deprivation and career decision self-efficacy: Influences of self-regulation and parental educational attainment. Career Development Quarterly, 65(2), 145-158. doi: 10.1002/cdq.12088

Taylor, M., \& Popma, J. (1990). An examination of the relationships among career decision-making self-efficacy, career salience, locus of control, and vocational indecision. Journal of Vocational Behavior, 37(1), 17-31. doi: 10.1016/0001-8791(90)90004-L 
Tien, H. L. S., Lin, C. H., \& Chen, S. C. (2005). A grounded analysis of career uncertainty perceived by college students in Taiwan. Career Development Quarterly, 54(2), 162-174. doi: 10.1002/j.2161-0045.2005.tb00148.x

Tolentino, L. R., Garcia, P. R. J. M., Toledano, L. S., Rafferty, A. E., \& Restubog, S. L. D. (2011). Differential moderating effects of student- and parent-rated support in the relationship between learning goal orientation and career decision-making self-efficacy. Journal of Career Assessment, 20(1), 22-33. doi: 10.1177/1069072711417162

Turner, S. L., Alliman-Brissett, A., Lapan, R. T., Udipi, S., \& Ergun, D. (2003). The career-related parent support scale. Measurement and Evaluation in Counseling and Development, 36(2). doi: 10.1080/07481756.2003.12069084

Widyaswara, I. W. E. (2016). Duh, banyak yang ngaku salah jurusan, AJI gali penyebab generasi muda enggan berwirausaha. Tribun Bali. Ditemu kembali dari https://bali.tribunnews.com/2016/12/28/duh-banyak-yang-ngaku-salah-jurusan-aji-galipenyebab-generasi-muda-enggan-berwirausaha

Zaroh, S. (2018). The impact of experimental learning techniques in improving the capability of career planning for students. Islamic Guidance and Counseling Journal, 1(2), 45. doi: 10.25217/igcj.v1i2.233 